\title{
Factors Influencing the Performance of Batik Authenticity Detection Application
}

\author{
Paminto Agung Christianto ${ }^{1}$, Restyandito ${ }^{2}$, Eko Budi Susanto ${ }^{3}$, Moh. Reza Maulana $^{4}$ \\ \{p_a_chr@yahoo.com ${ }^{1}$, dito@ti.ukdw.ac.id ${ }^{2}$,eqo_bs@yahoo.com ${ }^{3}$ \} \\ STMIK Widya Pratama, J1. Patriot 25, Pekalongan ${ }^{134}$, Universitas Kristen Duta Wacana, Jl. dr. \\ Wahidin Sudirohusodo 5-25, Yogyakarta ${ }^{2}$
}

\begin{abstract}
Currently there are many textiles with batik motif being sold in the market. Some customer bought these textiles because they are much cheaper than authentic batik cloth. However there are many instances where batik sellers take advantage of customers' ignorance, by selling textiles with batik motif as an authentic batik cloth. Hence this practices harm the customers. The application being developed make used of augmented reality to scan marker in a product's label, and display information about the authenticity of the product. This research investigates the effectiveness of the batik authenticity detection by considering different factors that might influence the performance of the application. Since the application may be used and operated by customers in different ways using various devices, it need to be tested on different environments. Factors being considered in this research were camera position relative to the marker, camera resolution, and browsers used to access the application.
\end{abstract}

Keywords: batik, image processing, augmented reality, authentification.

\section{Introduction}

There are three types of batik products namely batik tulis (drawn by hand using the canting tool), batik cap (waxed and chopped using copper stamp), and batik kombinasi (method of making batik using both hand drawn and chop stamp). Batik products have a high artistic value and a relatively expensive price because it is produced through a process that takes time and great effort and involves several people. Therefore, batik products are much sought after by the people. However, many people are lacking understanding about batik products and how they were made. Some parties were taking advantages of this condition by producing factory made textile using batik motif, hence it was produced faster and cheaper compared to the authentic batik products. These textiles are then sold in traditional market and wholesaler across Pekalongan causing confusion among lay people who can not distinguish between batik cloth and textile with batik motif. This situation is exacerbated by the presence of persons who exploit the ignorance of society by selling and claiming batik motif fabrics as an authentic batik cloth.This is clearly a detrimental practices for the customers.

In previous researches [1]-[3], the authors have developed an applications to detect the authenticity of batik cloth. The application was aimed to help customers identify whether the product is a genuine batik cloth or textile with batik motif before they bought it. Mobile Augmented technology was used because it is a technology which is readily available and relatively easy to use. Mobile Augmented has been used in many applications [4][5]. Product

ICCSET 2018, October 25-26, Kudus, Indonesia

Copyright (C) 2018 EAI

DOI 10.4108/eai.24-10-2018.2280612 
authenticity information can be provided after the application successfully scans the markers affixed to batik products. The library used to support augmented performance is the ar.js library which is a web-based augmented reality library developed by Jerome Etienne [6], [7]. In this paper, several tests were conducted to know the application performance and ideal environmental conditions.

To perform these tests, four environment conditions have been prepared, such as different camera resolution of the smartphone to be used; various scan distances and tiltes between the smartphone camera and marker; and several web browsers used to run the application. The data collected was analyzed using ANOVA to measure whether there are any significance differences in the application's performance on various environment conditions.

\section{Research Method}

The application testing was done by using 2 (two) web browser (namely Google Chrome and Mozile Firefox). to see the speed and clarity at which information appears after the marker was scanned, to see the clarity of information seen on the smartphone after a marker scanned and the speed at which information appears, the application testing was done by using 2 (two) web browser, namely Google Chrome and Mozilla Firefox.

The results of the scan were analyzed based on three independence variables, ie. camera resolution used to scan the marker, distance of the camera from the marker, and the tilt angle of the camera position relative to the marker. It is known that interaction style (the way people use their device) influence the effectiveness of an application [8]. The variables used to determine the clarity and speed are the distance and tilt angle scan. Data obtained were analyzed using separate one way analysis of variance with replication for each independence variables as follows:

\subsection{Distance and Tilt Angle}

To determine whether camera position influence the clarity of the results, following hypothesis were constructed based on various distances and tilt angles of the camera position,

Ho : there is no significance difference on the result's clarity

$\mathrm{Ha}:$ there is a significance difference on the result's clarity

Table 1. Independence Variables for Result's Clarity.

\begin{tabular}{lccc}
\hline & Id & Value Label & N \\
\hline Distance & 1 & $5 \mathrm{~cm}$ & 9 \\
& 2 & $10 \mathrm{~cm}$ & 9 \\
Tilt Angle & 3 & $15 \mathrm{~cm}$ & 9 \\
& 1 & $90^{\circ}$ & 9 \\
& 2 & $70^{\circ}$ & 9 \\
& 3 & $45^{\circ}$ & 9 \\
\hline
\end{tabular}


To test the clarity of information obtained by the application, marker were scanned using smartphone camera from various distances $(5 \mathrm{~cm}, 10 \mathrm{~cm}, 15 \mathrm{~cm})$ with three differents angle $\left(90^{\circ}, 70^{\circ}, 45^{\circ}\right)$

\subsection{Distance and Camera Resolution}

To determine whether distance and camera resolution influence the speed of the marker being recognized, following hypothesis were constructed,

Ho : there is no significance difference on the result's speed

$\mathrm{Ha}:$ there is a significance difference on the result's speed

Table 2. Independence Variables for Result's Speed.

\begin{tabular}{lccc}
\hline & Id & Value Label & N \\
\hline Distance & 1 & $5 \mathrm{~cm}$ & 9 \\
& 2 & $10 \mathrm{~cm}$ & 9 \\
\multirow{3}{*}{ Resolution } & 3 & $15 \mathrm{~cm}$ & 9 \\
& 1 & $5 \mathrm{Mp}$ & 9 \\
& 2 & $8 \mathrm{Mp}$ & 9 \\
& 3 & $13 \mathrm{Mp}$ & 9 \\
\hline
\end{tabular}

To test the speed of information obtained by the application, marker were scanned using smartphone camera from various distances $(5 \mathrm{~cm}, 10 \mathrm{~cm}, 15 \mathrm{~cm})$ using three differents resolution $(5 \mathrm{Mp}, 8 \mathrm{Mp}, 13 \mathrm{Mp})$

\section{Result and Discussion}

Eight tests were conducted on various variables, the results are as follows:

\subsection{Result of Information Clarity Test based on Object Distance and Camera Tilt Angle using Google Chrome Web Browser}

A one-way within subject ANOVA was conducted to compare the effect of object distance to camera and tilt angle on information clarity in three conditions. The result of information clarity test based on object distance and camera tilt angle using Google Chrome can be seen on Table 3. 
Table 3. First Test Result.

\begin{tabular}{lrrrrr}
\hline \multicolumn{1}{c}{ Source } & Type III Sum of Squares & Df & Mean Square & \multicolumn{1}{c}{ F } & \multicolumn{1}{c}{ Siq. } \\
\hline Corrected Model & $217,333^{\mathrm{a}}$ & 8 & 27,167 &, 190 &, 989 \\
Intercept & 21505,333 & 1 & 21505,333 & 150,192 &, 000 \\
Distance & 21,556 & 2 & 10,778 &, 075 &, 928 \\
Tilt Angle & 133,556 & 2 & 66,778 &, 466 &, 635 \\
Distance*Tilt Angle & 62,222 & 4 & 15,556 &, 109 &, 978 \\
Error & 2577,333 & 18 & 143,185 & & \\
Total & 24300,000 & 27 & & & \\
Corrected Total & 2794,667 & 26 & & & \\
\hline
\end{tabular}

R Squared = ,078 (Adjusted R Squared = -,332)

There was not a siginifant effect of object distance on information clarity at $p>0,05$ for the three conditions $[\mathrm{F}(2,27)=0,075, \mathrm{p}=0,928]$. Therefore we can accept ho: the result of information (marker) clarity were not affected by object distance. There was also not a siginifant effect of camera tilt angle on information clarity at $\mathrm{p}>0,05$ for the three conditions $[F(2,27)=0,466, p=0,635]$. Therefore we can accept ho: the result of information (marker) clarity were not affected by camera tilt angle.

\subsection{Result of Information Clarity Test based on Object Distance and Camera Tilt Angle using Mozilla Firefox Web Browser}

A one-way within subject ANOVA was conducted to compare the effect of object distance to camera and tilt angle on information clarity in three conditions. The result of information clarity test based on object distance and camera tilt angle using Mozilla Firefox can be seen on Table 4

Table 4. Second Test Result.

\begin{tabular}{lrrrrr}
\hline \multicolumn{1}{c}{ Source } & Type III Sum of Squares & Df & Mean Square & \multicolumn{1}{c}{ F } & \multicolumn{1}{c}{ Siq. } \\
\hline Corrected Model & $202,296^{\mathrm{a}}$ & 8 & 25,287 &, 206 &, 986 \\
Intercept & 19737,037 & 1 & 19737,037 & 160,851 &, 000 \\
Distance & 3,630 & 2 & 1,815 & 0,15 &, 985 \\
Tilt Angle & 162,296 & 2 & 81,148 &, 661 &, 528 \\
Distance*Tilt Angle & 36,370 & 4 & 9,093 &, 074 &, 989 \\
Error & 2208,667 & 18 & 122,704 & & \\
Total & 22148,000 & 27 & & & \\
Corrected Total & 2410,963 & 26 & & & \\
\hline
\end{tabular}

R Squared $=, 084$ (Adjusted R Squared $=-, 323$ )

There was not a siginifant effect of object distance on information clarity at $p>0,05$ for the three conditions $[\mathrm{F}(2,27)=0,15, \mathrm{p}=0,985]$. Therefore we can accept ho: the result of information (marker) clarity were not affected by object distance. There was also not a siginifant effect of camera tilt angle on information clarity at $\mathrm{p}>0,05$ for the three conditions $[F(2,27)=0,661, p=0,528]$. Therefore we can accept ho: the result of information (marker) clarity were not affected by camera tilt angle. 


\subsection{Result of Information Clarity Test based on Object Distance and Camera Resolution using Google Chrome Web Browser}

A one-way within subject ANOVA was conducted to compare the effect of object distance to camera and camera resolution on information clarity in three conditions. The result of information clarity test based on object distance and camera tilt angle using Google Chrome can be seen on Table 5 .

Table 5. Third Test Result.

\begin{tabular}{lrrrrr}
\hline \multicolumn{1}{c}{ Source } & Type III Sum of Squares & df & Mean Square & \multicolumn{1}{c}{ F } & Siq. \\
\hline Corrected Model & $2532,000^{\mathrm{a}}$ & 8 & 316,500 & 21,689 &, 000 \\
Intercept & 21505,333 & 1 & 21505,333 & 1473,716 &, 000 \\
Distance & 21,556 & 2 & 10,778 &, 739 &, 492 \\
Resolution & 2474,000 & 2 & 1237,000 & 84,769 &, 000 \\
Distance* Resolution & 36,444 & 4 & 9,111 &, 624 &, 651 \\
Error & 262,667 & 18 & 14,593 & & \\
Total & 24300,000 & 27 & & & \\
Corrected Total & 2794,667 & 26 & & & \\
\hline
\end{tabular}

R Squared = ,906 (Adjusted R Squared $=, 864$ )

There was not a siginifant effect of object distance on information clarity at $p>0,05$ for the three conditions $[\mathrm{F}(2,27)=0,739, \mathrm{p}=0,492]$. Therefore we can accept ho: the result of information (marker) clarity were not affected by object distance. There was a siginifant effect of camera resolution on information clarity at $\mathrm{p}<0,05$ for the three conditions $[\mathrm{F}(2$, $27)=84,769, p=0,000]$. Therefore we can reject ho: the result of information (marker) clarity were affected by camera resolution.

\subsection{Result of Information Clarity Test based on Object Distance and Camera Resolution using Mozilla Firefox Web Browser}

A one-way within subject ANOVA was conducted to compare the effect of object distance to camera and camera resolution on information clarity in three conditions. The result of information clarity test based on object distance and camera tilt angle using Mozilla Firefox can be seen on Table 6 .

Table 6. Fourth Test Result.

\begin{tabular}{lrrrrr}
\hline \multicolumn{1}{c}{ Source } & Type III Sum of Squares & \multicolumn{1}{c}{ df } & Mean Square & \multicolumn{1}{c}{ F } & \multicolumn{1}{c}{ Siq. } \\
\hline Corrected Model & $2156,296^{\mathrm{a}}$ & 8 & 269,537 & 19,051 &, 000 \\
Intercept & 19737,037 & 1 & 19737,037 & 1395,026 &, 000 \\
Distance & 3,630 & 2 & 1,815 &, 128 &, 880 \\
Resolution & 2143,185 & 2 & 1071,593 & 75,741 &, 000 \\
Distance* Resolution & 9,481 & 4 & 2,370 &, 168 &, 952 \\
Error & 254,667 & 18 & 14,148 & & \\
Total & 22148,000 & 27 & & & \\
\hline
\end{tabular}




$\frac{2410,963 \quad 26}{\text { Corrected Total }}$

There was not a siginifant effect of object distance on information clarity at $p>0,05$ for the three conditions $[\mathrm{F}(2,27)=0,128, \mathrm{p}=0,880]$. Therefore we can accept ho: the result of information (marker) clarity were not affected by object distance. There was a siginifant effect of camera resolution on information clarity at $\mathrm{p}<0,05$ for the three conditions $[\mathrm{F}(2$, $27)=75,741, p=0,000]$. Therefore we can reject ho: the result of information (marker) clarity were affected by camera resolution.

\subsection{Test Result of Information Display Speed based on Object Distance and Camera Tilt Angle using Google Chrome Web Browser}

A one-way within subject ANOVA was conducted to compare the effect of object distance to camera and tilt angle on information display speed in three conditions. The result of information display speed test based on object distance and camera tilt angle using Google Chrome can be seen on Table 7 .

Table 7. Fifth Test Result.

\begin{tabular}{lrrrrr}
\hline \multicolumn{1}{c}{ Source } & Type III Sum of Squares & df & Mean Square & \multicolumn{1}{c}{ F } & Siq. \\
\hline Corrected Model & $268,000^{\mathrm{a}}$ & 8 & 33,500 &, 231 &, 980 \\
Intercept & 20008,333 & 1 & 20008,333 & 137.953 &, 000 \\
Distance & 42,000 & 2 & 21,000 &, 145 &, 866 \\
Tilt Angle & 184,667 & 2 & 92,333 &, 637 &, 541 \\
Distance*Tilt Angle & 41,333 & 4 & 10,333 &, 071 &, 990 \\
Error & 2610,667 & 18 & 145,037 & & \\
Total & 22887,000 & 27 & & & \\
Corrected Total & 2878,667 & 26 & & & \\
\hline
\end{tabular}

R Squared = ,093 (Adjusted R Squared $=-, 310$ )

There was not a siginifant effect of object distance on information display speed at $p>0,05$ for the three conditions $[F(2,27)=0,145, p=0,866]$. Therefore we can accept ho: the result of information (marker) display speed were not affected by object distance. There was also not a siginifant effect of camera tilt angle on information clarity at $p>0,05$ for the three conditions $[\mathrm{F}(2,27)=0,637, \mathrm{p}=0,541]$. Therefore we can accept ho: the result of information (marker) display speed were not affected by camera tilt angle.

\subsection{Test Result of Information Display Speed based on Object Distance and Camera Tilt Angle using Mozilla Firefox Web Browser}

A one-way within subject ANOVA was conducted to compare the effect of object distance to camera and tilt angle on information display speed in three conditions. The result of information display speed test based on object distance and camera tilt angle using Mozilla Firefox can be seen on Table 8 . 
Table 8. Sixth Test Result.

\begin{tabular}{lrrrrr}
\hline \multicolumn{1}{c}{ Source } & Type III Sum of Squares & df & Mean Square & \multicolumn{1}{c}{ F } & \multicolumn{1}{c}{ Siq. } \\
\hline Corrected Model & $380,074^{\mathrm{a}}$ & 8 & 47,509 &, 366 &, 925 \\
Intercept & 17531,259 & 1 & 17531,259 & 134,933 &, 000 \\
Distance & 18,296 & 2 & 9,148 &, 070 &, 932 \\
Tilt Angle & 319,185 & 2 & 159,593 & 1,228 &, 316 \\
Distance*Angle & 42,593 & 4 & 10,648 &, 082 &, 987 \\
Error & 2338,667 & 18 & 129,926 & & \\
Total & 20250,000 & 27 & & & \\
Corrected Total & 2718,741 & 26 & & & \\
\hline
\end{tabular}

R Squared = ,140 (Adjusted R Squared $=-, 243$ )

There was not a siginifant effect of object distance on information display speed at $\mathrm{p}>0,05$ for the three conditions $[\mathrm{F}(2,27)=0,070, \mathrm{p}=0,932]$. Therefore we can accept ho: the result of information (marker) display speed were not affected by object distance. There was also not a siginifant effect of camera tilt angle on information display speed at $p>0,05$ for the three conditions $[\mathrm{F}(2,27)=1,228, \mathrm{p}=0,316]$. Therefore we can accept ho: the result of information (marker) display speed were not affected by camera tilt angle.

\subsection{Test Result of Information Display Speed based on Object Distance and Camera Resolution using Google Chrome Web Browser}

A one-way within subject ANOVA was conducted to compare the effect of object distance to camera and camera resolution on information display speed in three conditions. The result of information display speed test based on object distance and camera resolution using Google Chrome can be seen on Table 9 .

Table 9. Seventh Test Result.

\begin{tabular}{lrrrrr}
\hline \multicolumn{1}{c}{ Source } & Type III Sum of Squares & df & Mean Square & F & Siq. \\
\hline Corrected Model & $46,741^{\mathrm{a}}$ & 8 & 5,843 & 22,536 &, 000 \\
Intercept & 219,593 & 1 & 219,593 & 847,000 &, 000 \\
Distance & 1,407 & 2 &, 704 & 2,714 &, 093 \\
Resolution & 44,741 & 2 & 22,370 & 86,286 &, 000 \\
Distance*Resolution &, 593 & 4 &, 148 &, 571 &, 687 \\
Error & 4,667 & 18 &, 259 & \\
Total & 271,000 & 27 & & \\
Corrected Total & 51,407 & 26 & & \\
\hline
\end{tabular}

R Squared = ,909 (Adjusted R Squared $=, 869)$

There was not a siginifant effect of object distance on information clarity at $p>0,05$ for the three conditions $[\mathrm{F}(2,27)=2,714, \mathrm{p}=0,093]$. Therefore we can accept ho: the result of information (marker) display speed were not affected by object distance. There was a siginifant effect of camera resolution on information display speed at $p<0,05$ for the three 
conditions $[\mathrm{F}(2,27)=86,286, \mathrm{p}=0,000]$. Therefore we can reject ho: the result of information (marker) display speed were affected by camera resolution.

\subsection{Test Result of Information Display Speed based on Object Distance and Camera Resolution using Mozilla Firefox Web Browser}

A one-way within subject ANOVA was conducted to compare the effect of object distance to camera and camera resolution on information display speed in three conditions. The result of information display speed test based on object distance and camera resolution using Mozilla Firefox can be seen on Table 10 .

Table 10. Eight Test Result.

\begin{tabular}{lrrrrr}
\hline \multicolumn{1}{c}{ Source } & Type III Sum of Squares & df & Mean Square & F & Siq. \\
\hline Corrected Model & $2277,407^{\mathrm{a}}$ & 8 & 284,676 & 11,611 &, 000 \\
Intercept & 17531,259 & 1 & 17531,259 & 715,021 &, 000 \\
Distance & 18,296 & 2 & 9,148 &, 373 &, 694 \\
Resolution & 2222,519 & 2 & 1111,259 & 45,323 &, 000 \\
Distance*Resolution & 36,593 & 4 & 9,148 &, 373 &, 825 \\
Error & 441,333 & 18 & 24,519 & \\
Total & 20250,000 & 27 & & \\
Corrected Total & 2718,741 & 26 & & \\
\hline
\end{tabular}

R Squared $=, 838$ (Adjusted R Squared $=, 766$ )

There was not a siginifant effect of object distance on information clarity at $p>0,05$ for the three conditions $[\mathrm{F}(2,27)=0,373, \mathrm{p}=0,694]$. Therefore we can accept ho: the result of information (marker) display speed were not affected by object distance. There was a siginifant effect of camera resolution on information display speed at $\mathrm{p}<0,05$ for the three conditions $[\mathrm{F}(2,27)=45,323, \mathrm{p}=0,000]$. Therefore we can reject ho: the result of information (marker) display speed were affected by camera resolution.

\subsection{Discussion}

The experiments showed satisfactory result as the application able to detect the marker successfully under different conditions. This is an important factor contributing to the acceptance level by users. The application is expected to be used by users with various backgrounds (ability, experience, skills) and devices. Therefore, it should be effective even if the users are not so familiar with technology (non e-literate). As pointed out by Restyandito et al. non e-literate people may have difficulty operating mobile device hence influence the effectiveness of using an application [9]. As augmented reality becoming technologically possible and publicly available through mobile smartphone and tablet devices [5], it is expected that the batik authenticity detection application will be widely adopted by society. However, from this experiment, it was found that camera resolution affects the performance of the application. The application was aimed to be used by many people with various devices. Currently, there are still many devices with camera resolution less than 8MP. The ineffectiveness of the application to detect the marker may influence user's satisfaction and 
further the user acceptance. To improve the effectiveness of this application, further research need to be conducted. Some possible solutions to this problem are making bigger marker and more contrast color.

\section{Conclusion}

Based on the result from several tests, it can be concluded:

1) The application has successfully detect the marker and display the information with clarity regardless the camera position relative to the object (distance and tilt angle). Camera position also does not influence the information display speed.

2) The application was proven effective to display the information accurately using different web browsers.

3) Camera resolution influence the performance of the application. Higher resolution tend to yield better results (marker detection, information clarity and display speed). It is recommended to use camera with a minimum of $8 \mathrm{Mp}$ resolution.

4) The application can help customers to recognize an authentic batik cloth they bought.

\section{References}

[1] P. A. Christianto, E. B. Susanto, and I. Kurniawan, "Model Perlindungan Konsumen Batik dan Penjaga Keberlangsungan Batik Asli Kota Pekalongan Melalui Aplikasi E-Label Batik Yang Memanfaatkan Teknologi Augmented Reality Berbasis Cloud Computing," in SNATIF Ke-4 Tahun 2017, 2017.

[2] P. A. Christianto, E. B. Susanto, and I. Kurniawan, "Penerapan aplikasi e-label batik sebagai upaya mendukung penerapan peraturan daerah Kota Pekalongan nomor 6 tahun 2014," J. Litbang Kota Pekalongan, vol. 12, 2017.

[3] P. A. Christianto, E. B. Susanto, and I. Kurniawan, "Protecting Batik Customers and the Existence of Pekalongan Original Batik by Augmented Reality Technology Based on Cloud Computingin Batik Label," Int. J. Islam. Bus. Econ., vol. 1, no. 1, 2017.

[4] P. Kourothanassis, C. Boletsis, C. Bardaki, and D. Chasanidou, "Tourists responses to mobile augmented reality travel guides: The role of emotions on adoption behavior," Pervasive Mob. Comput., vol. 18, pp. 71-87, 2015.

[5] T. Liao and L. Humphreys, "Layar-ed places: Using mobile augmented reality to tactically reengage, reproduce, and reappropriate public space,” New Media Soc., vol. 17, no. 9, pp. 1418-1435, 2015 .

[6] J. Etienne, "Efficient Augmented Reality for the Web." [Online]. Available: https://github.com/jeromeetienne/AR.js. [Accessed: 10-Jul-2018].

[7] J. Martin and J. Bohuslava, "Augmented Reality as an Instrument for Teaching Industrial Automation," in Proceedings of the 29th International Conference 2018 Cybernetics \& Informatics (K\&I) Jan. 31 - Feb. 3, 2018, 2018.

[8] Restyandito and E. Kurniawan, "The Effect of Screen Size and Interaction Style on Mobile Device Usability,” Engineering Letters, vol. 25, no. 4, 2017.

[9] Restyandito, A. H. S. Chan, N. T. S. Saptadi, and A. W. Mahastama, "Design study for non eLiterate user: Case of mobile phone interface," in IAENG Transactions on Engineering Sciences, 1st Edition, S. Ao, A. H.-S. Chan, H. Katagiri, and L. Xu, Eds. CRC Press, 2014, pp. 301-310. 